\title{
Overcoming the Challenge of Legacy Learning Methods
}

\author{
Kathaleen Reid-Martinez *
}

Recognizing the role of the leader points to the importance of how leaders are trained and developed so that they are capable of helping their institutions maintain the values of their organizations. This was found to be a concern of the defense and security leaders of the newly developed independent sovereign states of the USSR. As many of them installed democratic forms of government, the challenge was not just to declare education for reform on paper, but how to transform their educational institutions to develop leaders for the directions that had been set by their newly formed governments.

This concern for sustaining institutions is in keeping with much research in the field of leadership. Leadership's role in sustaining institutional and societal culture and in driving institutional change is clearly pointed out by experts such as Burt Nanus, who focused on visionary leadership; the late Peter Drucker, who emphasized the growth of future leaders; and Warren Bennis, who underlined the importance of developing leaders to become leaders of leaders. ${ }^{1}$ Additional recognition of the leader's significance in both sustaining and changing culture is found in Brady's work, ${ }^{2}$ where he cited 2001 research conducted by the public relations firm Burson-Marsteller examining the top thirty CEOs of publicly traded companies in Germany. The results showed that approximately twothirds of the public reputation of a company was determined by the leader of the organization. In keeping with this, a later Burson-Marsteller study done in the United States examined 1155 key stakeholders, and determined that the CEO's reputation contributed significantly to how companies are perceived. Brady pointed to leaders such as Lord Browne at BP, Chad Holliday at DuPont, Michael W. Crooke at Patagonia, and Ben Cohen at Ben and Jerry's, who have understood that their legacies as leaders established the tone and sustainability of their organizations and made this an organizational priority.

To be successful in leadership development at defense and security educational institutions requires that the educational processes themselves be examined. Following NATO's Partnership Action Plan for Defense Institution Building (PAP-DIB) and Education for Defense Reform initiatives (2004-05), the Partnership for Peace Consortium's (PfPC) Educators Development Working Group (ED WG) created a sub-group of the

\footnotetext{
Kathaleen Reid-Martinez is Provost at Mid-America Christian University in Oklahoma City, OK. She serves as an advisor for leadership education to the Partnership for Peace Consortium and to the Geneva Institute for Leadership and Public Policy.

1 Burt Nanus, Visionary Leadership: Creating a Compelling Sense of Direction for Your Organization (San Francisco: Jossey-Bass, 1992); Peter F. Drucker, "Forward," in The Leader of the Future, ed. F. Hesselbein, M. Goldsmith, and R. Beckhard (San Francisco: Jossey-Bass, 1996), xi-xv; and Warren Bennis, "Becoming a Leader of Leaders," in Rethinking the Future, ed. R. Gibson (London: Nicholas Brealey Publishing, 1998), 148-63.

2 Arlo Kristjan O. Brady, The Sustainability Effect: Rethinking Corporate Reputation in the 21st Century (New York: Palgrave Macmillan, 2005).
} 
same name to tackle the challenge of how to transform the legacy teaching methods of authoritarian institutions into democratic learning processes that promoted education for defense reform within these countries so that they could train the leaders that would be required for the twenty-first century. More specifically, the challenge was how to help transform an authoritarian, top-down, teacher-centered approach to education that was based most often in the lecture method into a shared, collaborative learning process that exhibited democratic values, not just as curriculum content or an end state but as a democratic process and means of learning resulting in transformative leadership education.

\section{Educators Development Working Group Response}

The response of the Educators Development Working Group was to approach learning from a three-fold perspective, and to develop active working teams around each prong:

1. What to teach, which included curricula for defense institution building and professional military education

2. Defense education enhancement programs tailored for each participating nation

3. How to teach, which included annual multinational educators' workshops and local national educator programs.

The goal of the latter, and the focus of this article, was to share and instill Western learning and teaching methods with Partner defense educators. This included an emphasis on learner-centered education, with its collaborative knowledge building capacity, assessment, and community building. The approach was embedded in democratic values central to education for defense reform. Critical values for reform included accountability, integrity, transparency, pluralism, tolerance, and respect. These were not just addressed directly as content by the ED WG sub-team (referred to hereafter as the ED WG faculty team) actively working on this topic of how to teach, but rather as lived practice within the experiences the team provided the learners.

The underlying goals of the ED WG faculty team focused on how to teach are threefold. The first goal is to bring about a broader and more concrete understanding of democratic values, and of how those values simultaneously influence not just the end state but also the process of learning within defense and security institutions. The second goal is to assist the learners in becoming part of communities of best practices in both teaching and learning. This opportunity is offered through the networks that opened within each of the learning experiences. The third goal is the development of a life-long approach to learning so that attendees no longer view learning as a static event, but rather understand their ongoing responsibility as a member of a contemporary learning society. This requires educators to constantly seek out opportunities to continue learning, whether on an individual basis or within formal learning programs.

Two venues were originally chosen to help accomplish these goals. The first venue was (and continues to be) a multinational program that meets once a year. Participants from multiple member nations of the Partnership for Peace (PfP) meet to learn and share best practices in learner-centered education. Since 2007, over 150 participants have been certified as attending the multi-national Annual Educators' Programs. 
The second venues are the national programs that meet within a selected nation and draw participants from only that nation. These national programs are connected to the Defense Education Enhancement Program (DEEP) initiatives of the PfPC. These programs may meet one to three times (or even more) within any given country, depending upon that nation's needs assessments. Assessments help to demonstrate when the nation has attained a sufficiently strong understanding and practice of the new concepts. The time frame for national programs within a given nation could be a few months to a few years, depending upon circumstances.

A third venue has recently opened, as the ED WG faculty team has come to work alongside content experts on selected topics. In response to the NATO and Partnership for Peace country requirements on this topic in the past couple of years, the ED WG joined with the Security Sector Reform (SSR) Working Group of the PfPC to help in the arena of gender and security. In these venues, educational experts from the ED WG faculty team work alongside the gender content experts from the SSR to assist individuals responsible for disseminating an understanding of the role of gender in security in their nations. In assessments of this need, the working groups recognized that a key approach to this dissemination process included instruction of how to teach and train at the operational, tactical, and strategic levels. In response, the ED WG faculty team assisted the SSR in helping over thirty-five key individuals in two different events to better understand the learning processes and teaching methods needed for this highly specialized topic.

Opportunities to network with fellow educators from multiple geographic locations - both within a nation and across nations - are built into these programs, and are actively promoted within all three conference-style venues. This intentional networking, especially across nations, provides rich opportunities for continued growth and development as participants learn to share best learning and teaching practices with each other. In addition to the networking opportunities that are available during the conferences, participants can continue their networking via the PfPC Portal. This electronic portal provides an archive of teaching and learning resources for participants as well as interactive spaces for these learners to continue sharing their learning and teaching experiences following the conferences. Further development of this portal will invite participants to continue in their pursuit of life-long learning and best practices of teaching and learning as participants share with each other throughout their careers.

\section{Theoretical Approaches}

From a theoretical perspective, the ED WG faculty team is driven by different approaches to the learning process. To be successful in its goals, the ED WG faculty team primarily grounds its work in current understandings of adult learners. A key aspect of these types of learners is their requirement to be life-long learners in rapidly changing societies that must move from information overload to constructing knowledge and wisdom based upon the vast amounts of information now available to them and their institutions. The two theoretical approaches used to help them with this movement are constructivism and connectivism. 


\section{Constructivism}

The primary learning theory used by the ED WG faculty team is what is often referred to as a constructivist approach. ${ }^{3}$ This approach recognizes that learners create meaning by ordering their understanding of the world through their own filters and learning experiences. This creates one of the deepest levels of learning. Thus, an individual's first-hand learning experience creates a trustworthy development of knowledge as the learner acts within and upon the context of learning to acquire and test his or her understanding. In keeping with this, a primary goal of each of the ED WG faculty team programs is to help participants shift their focus from teaching to learning. The former is all too often presented as a passive one-way approach to learning that simply provides information, most often through the lecture method. The focus on learning, on the other hand, encourages participants to become actively involved in the learning process. Thus, rather than simply discussing traditional one-way teaching techniques per se, the ED WG faculty teams choose to emphasize how to learn with its attendant student learning outcomes. To support this, team members lead participants through multiple active learning methods to expand their repertoire of learning methods and help them to understand how to more fully engage learners to enhance their educational experience.

The most important assistance provided by the ED WG faculty team is helping the participants in each venue to understand the changing role of the professor within the classroom. This forces participants to view the role of the learner as being active rather than passive in the learning process. Grooms' Interaction Model (shown in Figure 1 below) clearly demonstrates this shift. ${ }^{4}$ This model is based on research by Kidd, Long, Moore, and Palmer (among others), and shows how learners in a constructive environment constantly interact with the content of the learning, fellow peers in the learning process, and the facilitator. ${ }^{5}$ In this model, the professor has become a facilitator in the learning process, which is more conducive to a democratic approach, rather than an authoritarian approach to learning.

Grooms' model is consistent with the work of Duffy and Cunningham, which suggests "learning is an active process of constructing ... knowledge and ... instruction is a

3 See Peter L. Berger and Thomas Luckmann, The Social Construction of Reality: A Treatise in the Sociology of Knowledge (Garden City, NY: Anchor Books, 1967); L.S. Vygotsky, Mind in Society: The Development of Higher Psychological Processes (Cambridge, MA: Harvard University Press, 1978).

4 See Linda D. Grooms, "Interaction in the Computer-mediated Adult Distance Learning Environment: Leadership Development through Online Education," Dissertation Abstracts International 61:12 (2000): 4692A.

5 J. Roby Kidd, How Adults Learn (Chicago: Follett Publishing, 1973); Huey B. Long, Adult Learning: Research and Practice (New York: Cambridge University Press, 1983); Michael G. Moore, "Editorial: Three Types of Interaction," The American Journal of Distance Education 3:2 (1989): 1-7; and Parker J. Palmer, To Know as We Are Known: Education as a Spiritual Journey (San Francisco: Harper Collins, 1993). 


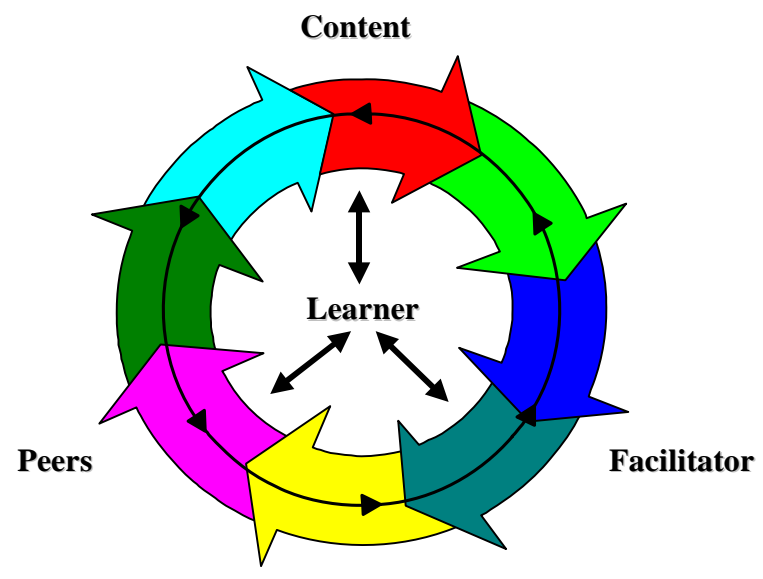

Figure 1: Learner Interaction Model.

process of supporting that construction.." As noted above, this requires a shift in understanding the role of the professor, in keeping with the model put forth by Grooms above.

In this approach to learning, the professor's role must be understood more as the "guide on the side," or someone who facilities the learning of content, rather than the "sage on the stage" who primarily provides information to the learner via lecture. The "guide on the side" approach to learning that emphasizes the role of the individual learner actively promotes values such as responsibility, accountability, and integrity in the learning process. These values are highly consistent with the democratic values promoted by the ED WG.

The following table indicates the differences in approaches to learning as it delineates between the active learner (often referred to as an autonomous learner), and the learner as a passive receiver of information. ${ }^{7}$

6 Thomas M. Duffy and Donald J. Cunningham, "Constructivism: Implications for the Design and Delivery of Instruction," in Handbook of Research for Educational Communications and Technology, ed. D. H. Jonassen (New York: Simon \& Schuster, 1996), 171.

7 Table is drawn from Kathaleen Reid-Martinez, Linda Grooms, and Mihai Bocarnea, "Constructivism in Online Distance Education," in Encyclopedia of Information Science and Technology, Second edition (Hersey: IGI Global Publishing, 2008), and is based upon Herman G. Weller, "Interactivity in Microcomputer-based Instruction: Its Essential Components and How It Can Be Enhanced," Educational Technology 28:2 (1988): 23-27; Albert Bandura, Social Learning Theory (Englewood Cliffs, NJ: Prentice Hall, 1977) and Bandura, "Self-efficacy," in Encyclopedia of Human Behavior, Vol. 4, ed. V.S. Ramachaudran (New York, NY: Academic Press, 1994), 77-81. 
Table 1. Approaches to Learning.

\begin{tabular}{|l|l|l|}
\hline \multirow{2}{*}{ Professor } & Traditional & Constructivist \\
\hline \multirow{2}{*}{ Learner } & "Sage on the stage" & "Guide on the side" \\
\cline { 2 - 3 } Knowledge & Content provider & Content facilitator \\
\hline Organization of learning & Passive recipient & Active participant \\
\hline Communication & Fixed object & Fluid \\
\hline Primary Resource & Uni-directional & Open and often chaotic \\
\hline Method & Text and professor & Multi-directional \\
\hline Media & Lecture & Active process \\
\hline Format & Print & Blended \\
\hline Activities & Individualized & Collaborative \\
\hline Focus of Learning & Goal-oriented & Problem-centered \\
\hline Assessment & standing & $\begin{array}{l}\text { Application, analysis, } \\
\text { synthesis, and evaluation }\end{array}$ \\
\hline Community & Recall & Alternative assessment \\
\hline
\end{tabular}

This shift is important not only because it aids the learning process, but also because it allows participants to practice and exhibit new values as the ED WG faculty team models the behavior and helps participants to practice this new approach. This is in direct contrast with the approach that was historically in use in most PfP countries. Most participants in the ED WG programs have previously learned through lectures that were provided by the most respected senior officers within their nations, a process that reinforced the authoritarian approach to defense education and resulted in reinforcement of the status of the authoritarian leader.

As is pointed out by John Berry in another article in this volume, some of the more advanced defense and security institutions used question-and-answer approaches to assist in the teaching process, but all too often these institutions did not allow the approach to challenge the sacred role of the respected authority at the front of the classroom. In contrast, helping the participants to use more active, group-based constructivist approaches opened up the ED WG participants to new processes and values in their learning. This helps to develop and promote a more collaborative leadership style among participants, a leadership approach that is more responsive to the needs of contemporary 
society. In this way, the EW WG process challenges the participants' understanding of traditional approaches to authority in the classroom, which in turn promotes a healthier, more collaborative democratic leadership approach to the current stage of defense and security development in contemporary society.

\section{Connectivism}

In addition to the role of social constructivism as outlined above, connectivism is recognized as another important theoretical approach that is represented in the ED WG faculty team. ${ }^{8}$ Simply put, this approach points to the reality that learning does not occur just within the confines of an educational building, but within the full context of an individual's life. In this sense, helping learners to expand their networks to include fellow peers in education becomes a critical component in enhancing participants' learning. Their ability to stay connected with peers both at home and abroad expands a learner's ability to use multiple contexts to gather knowledge useful to him or her within the learning process. Thus, the role of interactive communication technology, such as the PfPC portal, plays an important role in helping learners to glean new information from multiple sources at any given time and place.

Additionally, this connectivist approach includes exposing participants to the array of experts that is available to them electronically. In the learning venues, ED WG participants have technology that allows them access multiple databases. Such interactive learning experiences allow the participants to understand more about the regional and global experts who are available as resources. In the digital communities of best practices that comprise these experts, the participants as learners use a constructivist approach to gather what they need to promote best practices of learning within their particular nation's context.

In the process of helping them to connect with peers and global experts, the ED WG faculty team plays an important role in helping the participants to sift through these multiple sources of information and to integrate what they learn within the broader community of practice. Here they can collaboratively bring theirs and others' worldviews and experiences into a common learning community. As they do so, the participants, especially in the multi-national programs, negotiate and create meaning within themselves and with others as they share knowledge and participate together in common learning experiences. In this connected constructivist approach, education is no longer the pursuit of one individual, but rather becomes a regionally collaborative process that reciprocally shapes both the participant as an individual and simultaneously informs the entire learning community. This connected process refines and often redefines participants' values. Such transformation creates an environment that is supportive of the democratic forms of learning promoted by the PfP Consortium.

8 The most cogent description of this approach can be found in George Siemens, "Connectivism: A Learning Theory for the Digital Age," International Journal of Instructional Technology and Distance Learning 2:1 (2005); available at http://www.itdl.org/Journal/Jan_05/ article01.htm. 


\section{Conclusion}

From this framework of constructivist and connectivist learning promoted by the ED WG faculty team, six critical principles for sustainable learning that challenges legacy learning methods can be drawn. Such learning approaches should:

1. Promote life-long learning in leaders

2. Secure success over time through long-range collaborative approaches

3. Promote leaders developing and mentoring other leaders as they connect with colleagues and experts around the world

4. Encourage democratic values through an educational process, not just ideals

5. Develop diversity and increased capacity as collaborative networking promotes the value of different voices and approaches to problem solving and leadership in today's complex society

6. Harness human capacity and resources as collaboration and networking is promoted.

By using this framework, these principles support change within the Partner country. The ED WG faculty teams have consistently observed transformation within the participants over the period of education programs offered in multiple venues. Change is most seen in those who participate in the national DEEP venues, and then subsequently attend the multinational programs. Change is also noted in those who attend more than one multinational program. Research is currently under way to review the long-term impact on those who attend only one venue.

What is consistently shown, even after only one program, is that participants who become fully engaged in the venue's learning opportunities experience the capacity to understand changes needed within their institutions and the value of those changes. Participants who learn to connect with peers and global experts, sift through multiple sources of data on learning best practices, and serve as facilitators of knowledge building rather than disseminators of information demonstrate within the ED WG faculty team workshops the dynamic and transformative nature of this learner-centered approach to defense and security education. In this process, these educational leaders as participants in the program use a constructivist approach to glean what they need to meet their learning needs in their individual context. As the participants practice the values of this learner-centered approach, they grasp how this process promotes life-long learning, which is essential in rapidly changing cultural contexts.

Parallel with this experience, participants can see the reciprocal nature of how the community shapes the individual as well as how the individual shapes the community. This shift in worldview lets them see the need for transformative leadership that values such reciprocity within their communities. This suggests that such a democratic process to learning influences participants' values, not just with regard to learning, but also of leadership, since they can recognize the value of collaboration in response to the complex needs of their institutions that now operate in global contexts, rather than only resorting to authoritarian approaches to problem solving. In the process, they as educa- 
tional leaders can see and practice this parallel between life-long learning and healthy leadership, which recognizes that leadership grounded in collaborative democratic values can result in sustainable leadership within their evolving defense communities.

As the above suggests, the participants in the ED WG faculty team programs learn multiple ways to create change through new educational initiatives in their home defense and security institutions. These educational endeavors promote and foster changes in worldviews and approaches to leadership through the process of learning in new forms and methods of education. This allows the reach of the ED WG faculty teams to extend beyond simply educating the educators to serving as a catalyst of transformation for defense and security institutions. Indeed, it promotes and expands the ED WG goal to increase knowledge-building capacity and community building by enhancing an institution's leadership development initiatives. 


\section{Bibliography}

Bandura, Albert. "Self-efficacy." In Encyclopedia of Human Behavior, 77-81. Vol. 4. New York, NY: Academic Press, 1994.

Bandura, Albert. Social Learning Theory. Englewood Cliffs, NJ: Prentice Hall, 1977.

Bennis, Warren. "Becoming a Leader of Leaders." In Rethinking the Future, 148-63. London: Nicholas Brealey Publishing, 1998.

Berger, Peter L., and Thomas Luckmann. The Social Construction of Reality: A Treatise in the Sociology of Knowledge . Garden City, NY: Anchor Books, 1967.

Brady, Arlo Kristjan O.. The Sustainability Effect: Rethinking Corporate Reputation in the 21st Century. New York: Palgrave Macmillan, 2005.

Drucker, Peter F.. "Forward." In The Leader of the Future, xi-xv. San Francisco: Jossey-Bass, 1996.

Duffy, Thomas M., and Donald J. Cunningham. "Constructivism: Implications for the Design and Delivery of Instruction." In Handbook of Research for Educational Communications and Technology, 171. New York: Simon \& Schuster, 1996.

Grooms, Linda D.. "Interaction in the Computer-mediated Adult Distance Learning Environment: Leadership Development through Online Education." Dissertation Abstracts International 61, no. 12 (2000): 4692A.

J. Kidd, Roby. How Adults Learn. Chicago: Follett Publishing, 1973.

Long, Huey B.. Adult Learning: Research and Practice. New York: Cambridge University Press, 1983.

Moore, Michael G.. "Editorial: Three Types of Interaction." The American Journal of Distance Education 3, no. 2 (1989): 1-7.

Nanus, Burt. Visionary Leadership: Creating a Compelling Sense of Direction for Your Organization. San Francisco: Jossey-Bass, 1992.

Palmer, Parker J.. To Know as We Are Known: Education as a Spiritual Journey. San Francisco: Harper Collins, 1993.

Reid-Martinez, Kathaleen, Linda Grooms, and Mihai Bocarnea. "Constructivism in Online Distance Education." In Encyclopedia of Information Science and Technology. Second ed. Hersey: IGI Global Publishing, 2008. 
Siemens, George. "Connectivism: A Learning Theory for the Digital Age." International Journal of Instructional Technology and Distance Learning 2, no. 1 (2005).

Vygotsky, L.S.. Mind in Society: The Development of Higher Psychological Processes. Cambridge, MA: Harvard University Press, 1978.

Weller, Herman G.. "Interactivity in Microcomputer-based Instruction: Its Essential Components and How It Can Be Enhanced." Educational Technology 28, no. 2 (1988): 23-27. 